\title{
Line Mixing in Water Vapor and Methane
}

\author{
M. A. H. Smith, ${ }^{1}$ L. R. Brown, ${ }^{2}$ R. A. Toth, ${ }^{2}$ V. Malathy Devi ${ }^{3}$ and D. \\ Chris Benner ${ }^{3}$ \\ ${ }^{1}$ Science Directorate, NASA Langley Research Center, \\ Mail Stop 401A, Hampton, VA 23681-2199, U. S. A. \\ 2 Jet Propulsion Laboratory, California Institute of Technology, \\ 4800 Oak Grove Dr., Pasadena, CA 91109-8099, U. S. A. \\ ${ }^{3}$ Department of Physics, The College of William and Mary, \\ Box 8795, Williamsburg, VA 23187-8795, U. S. A.
}

\begin{abstract}
A multispectrum fitting algorithm has been used to identify line mixing and determine mixing parameters for infrared transitions of $\mathrm{H}_{2} \mathrm{O}$ and $\mathrm{CH}_{4}$ in the 5-9 $\mu \mathrm{m}$ region. Line mixing parameters at room temperature were determined for two pairs of transitions in the $v_{2}$ fundamental band of $\mathrm{H}_{2}{ }^{16} \mathrm{O}$, for self-broadening and for broadening by $\mathrm{H}_{2}, \mathrm{He}, \mathrm{CO}_{2}, \mathrm{~N}_{2}, \mathrm{O}_{2}$ and air. Line mixing parameters have been determined from air-broadened $\mathrm{CH}_{4}$ spectra, recorded at temperatures between $210 \mathrm{~K}$ and $314 \mathrm{~K}$, in selected R-branch manifolds of the $v_{4}$ band. For both $\mathrm{H}_{2} \mathrm{O}$ and $\mathrm{CH}_{4}$, the inclusion of line mixing was seen to have a greater effect on the retrieved values of the line shifts than on the retrieved values of other parameters.
\end{abstract}

Keywords: Infrared, line mixing, water vapor, methane, line broadening, line shifts.

PACS: 33.20.-t, 33.20.Ea, 33.70.Jg

\section{INTRODUCTION}

A multispectrum fitting algorithm [1], used to analyze pressure-broadening and line shift parameters for transitions of $\mathrm{H}_{2} \mathrm{O}$ and $\mathrm{CH}_{4}$ in the 5-9 $\mu \mathrm{m}$ region, has revealed the characteristic residual patterns due to line mixing between specific transitions within each band. In this paper we will describe observations and quantitative analyses of line mixing in the $v_{2}$ fundamental band of $\mathrm{H}_{2}{ }^{16} \mathrm{O}$ and in the $v_{4}$ fundamental band of $\mathrm{CH}_{4}$. These are the first laboratory measurements of line mixing parameters in each band.

\section{WATER VAPOR}

For two pairs of transitions in the $v_{2}$ fundamental band of $\mathrm{H}_{2}{ }^{16} \mathrm{O}$, the characteristic residuals of line mixing were observed very distinctly in least-squares fits of highresolution FTS spectra of self-broadened $\mathrm{H}_{2} \mathrm{O}$ at pressures up to 29 Torr and mixtures of $\mathrm{H}_{2} \mathrm{O}$ with $\mathrm{H}_{2}, \mathrm{He}, \mathrm{CO}_{2}, \mathrm{~N}_{2}, \mathrm{O}_{2}$ and air at pressures up to 999 Torr [2]. The positions 
and rotational assignments of the four lines (in terms of the rotational quantum numbers $\mathrm{J}, \mathrm{K}_{\mathrm{a}}$ and $\mathrm{K}_{\mathrm{c}}$ ) are given as follows:

$P$ branch: $\left(\begin{array}{lll}1 & 0 & 1\end{array}\right) \leftarrow\left(\begin{array}{lll}2 & 1 & 2\end{array}\right)$ at $1539.061 \mathrm{~cm}^{-1}$ mixing with $\left(\begin{array}{lll}2 & 1 & 2\end{array}\right) \leftarrow\left(\begin{array}{lll}3 & 0 & 3\end{array}\right)$ at $1540.300 \mathrm{~cm}^{-1}$;

$R$ branch: $\left(\begin{array}{lll}3 & 0 & 3\end{array}\right) \leftarrow\left(\begin{array}{lll}2 & 1 & 2\end{array}\right)$ at $1652.400 \mathrm{~cm}^{-1}$ mixing with $\left(\begin{array}{lll}2 & 1 & 2\end{array}\right) \leftarrow\left(\begin{array}{lll}1 & 0 & 1\end{array}\right)$ at $1653.267 \mathrm{~cm}^{-1}$.

Note that in each pair of lines, the rotational quantum numbers of the upper state of one transition ( $\left.\begin{array}{lll}2 & 1 & 2\end{array}\right)$ are the same as those of the lower state of the other transition.

For each broadening gas, groups of three to seven spectra were analyzed [2] to determine line positions, intensities, halfwidths, pressure-induced shifts and offdiagonal relaxation matrix elements. Each group of spectra was analyzed first using the multispectrum algorithm assuming Voigt line shapes and no line mixing, and then the analysis was repeated with line mixing implemented, allowing the off-diagonal relaxation matrix elements [3] to be determined in the least-squares fit. The observed spectra and residuals from the fits of self-broadened spectra are shown in Fig. 1.
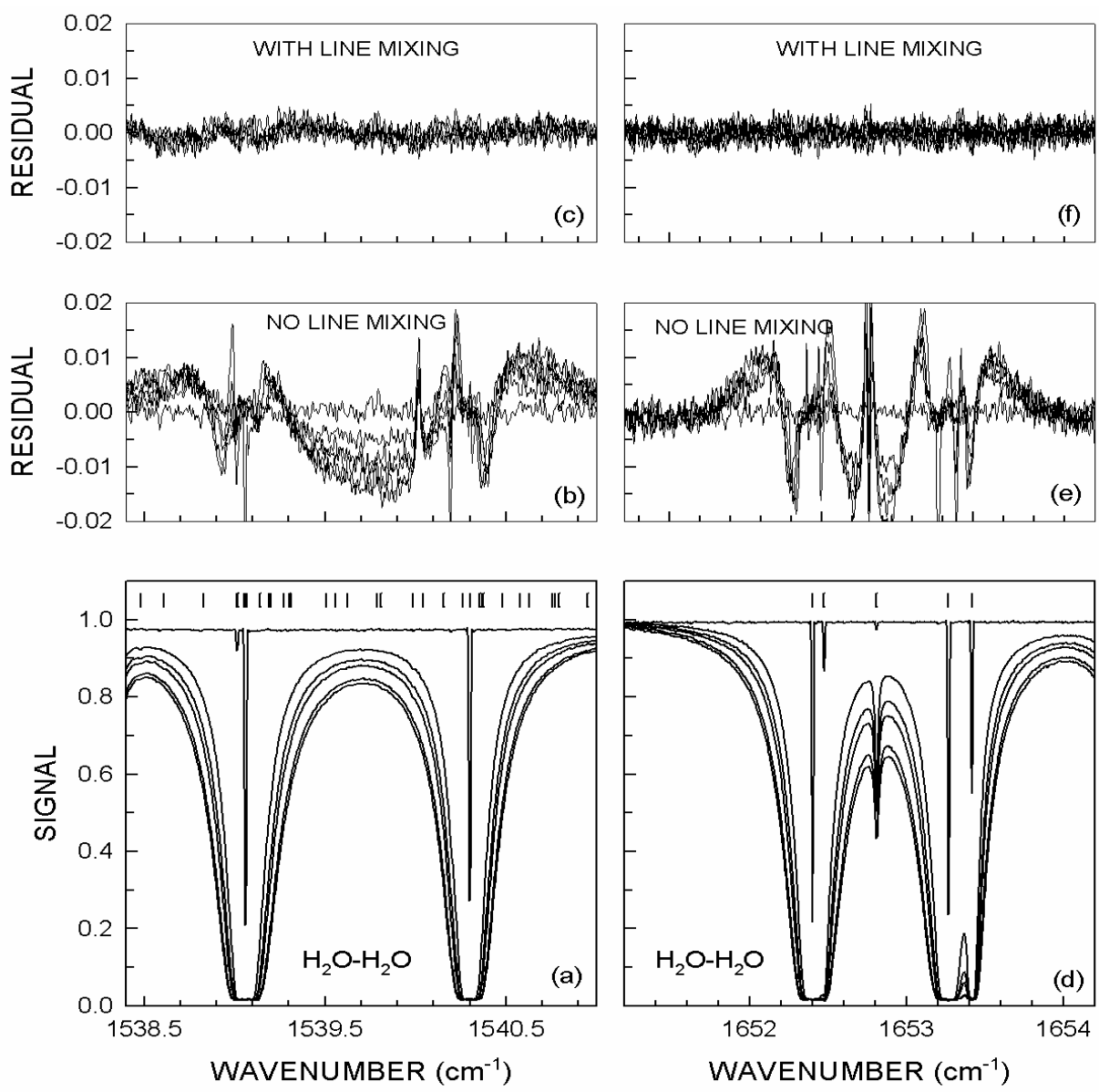

FIGURE 1. Multispectrum fits of mixed pairs of self-broadened $\mathrm{H}_{2} \mathrm{O}$ lines in the $\mathrm{P}$ branch (left panels) and $\mathrm{R}$ branch (right panels) of the $\mathrm{v}_{2}$ band. Observed spectra, at six different water pressures ranging from 0.01 to 29 Torr, are plotted in the bottom panels (a, d) along with tick marks indicating the line positions. Middle panels (b, e) show (Obs. - Calc.) residuals for the Voigt line shape without line mixing, and the upper panels (c, f) show the corresponding residuals for the fits with line mixing [2]. 
The characteristic residuals of a pair of mixed lines are seen most clearly in the middle left panel of Fig.1, where the calculations without line mixing overestimate the absorption between the two strong $\mathrm{P}$ branch lines and underestimate the absorption in the wings of the mixed pair. The zig-zag residuals near the line centers also indicate that the line positions and/or pressure-induced shifts are not well-determined. For the $\mathrm{R}$ branch pair, which is overlapped by some other lines, the pattern of residuals is less obvious but still discernable.

Since all of the $\mathrm{H}_{2} \mathrm{O}$ spectra had been recorded with samples near room temperature, the temperature dependences of the broadening, shift, and line mixing parameters could not be determined. However, it was possible to compare the mixing parameters retrieved for the various broadening gases. For the two pairs of $v_{2}$ transitions analyzed, the largest mixing effects were observed for self-broadening and $\mathrm{H}_{2}$-broadening, and the smallest effects were found for He-broadening.

While inclusion of line mixing in the fits did not significantly change the retrieved line intensities and widths (except for self- and $\mathrm{H}_{2}$-broadening), the retrieved values of the pressure-induced shifts were affected by mixing for all broadeners except He.

Details of this study may be found in the journal article of Brown et al. [2].

\section{METHANE}

Multispectrum fits of air-broadened $\mathrm{CH}_{4}$ spectra, recorded at temperatures between $210 \mathrm{~K}$ and $314 \mathrm{~K}$ and broadening gas pressures between 50 and 550 Torr, have been carried out for selected R-branch manifolds in the $v_{4}$ band. An example of fits with and without line mixing in the $\mathrm{R}(11)$ manifold is shown in Fig. 2. In this figure it is apparent from the residuals that most of the line mixing is occurring between transitions on the low-wavenumber side of the manifold. Examination of the retrieved relaxation matrix elements verifies this initial observation, as the mixing parameters for transitions on the high-wavenumber side of the manifold are effectively zero. Some self-broadened $\mathrm{CH}_{4}$ spectra were also included in this fit, but the results are very preliminary since only 15 spectra were included out of 64 possible spectra that can be used in the final analysis.

Another interesting spectral region is the $\mathrm{R}(3)$ manifold of ${ }^{12} \mathrm{CH}_{4}$, which is overlapped by the $\mathrm{R}(5)$ manifold of ${ }^{13} \mathrm{CH}_{4}$. A set of 31 spectra was fit in this region to determine broadening, shift, and line mixing parameters in both manifolds. The observed spectra and residuals from the fit with line mixing are shown in Fig. 3. 

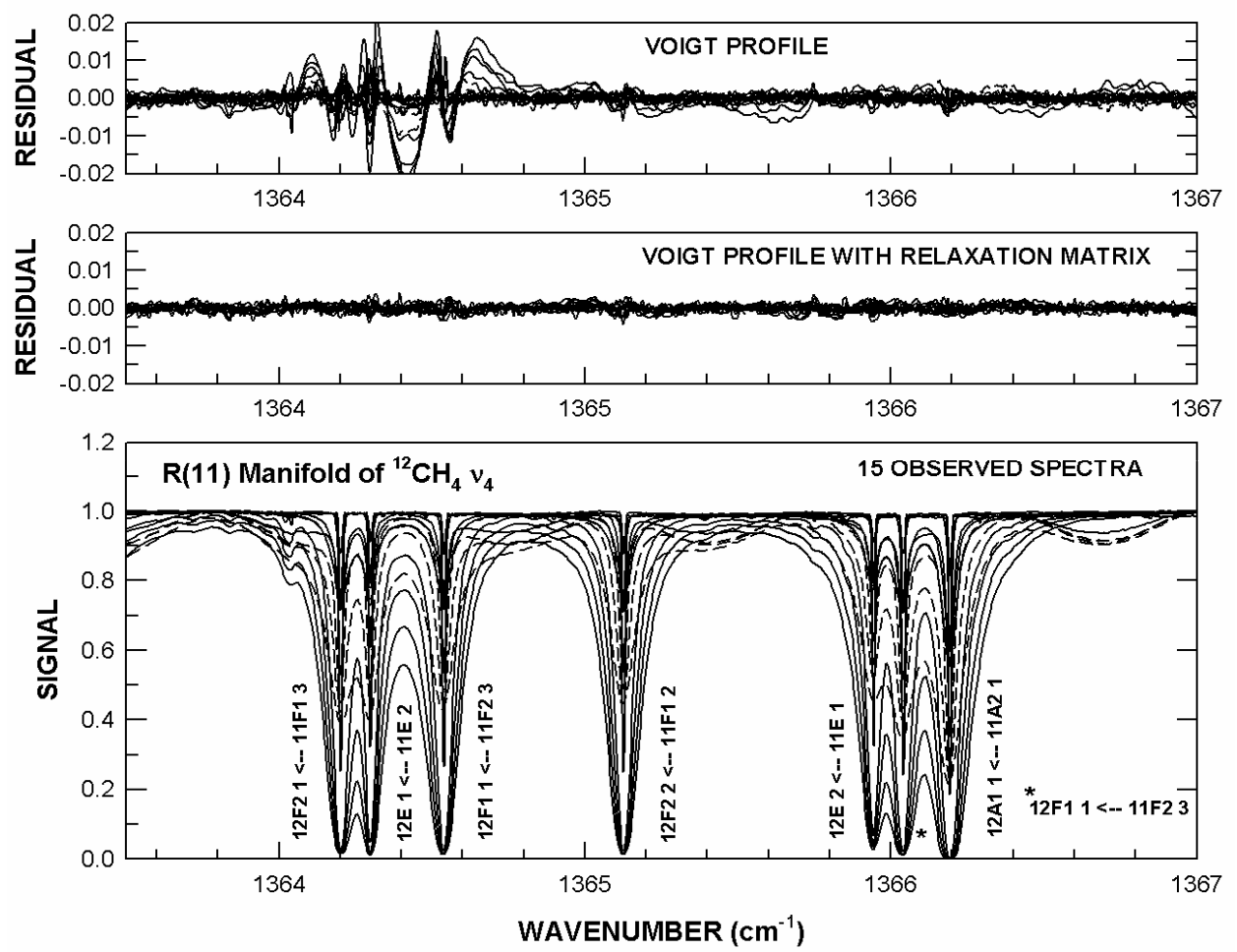

FIGURE 2. Fits of 15 air- and self-broadened room-temperature $\mathrm{CH}_{4}$ spectra with and without line mixing. Maximum pressure is 550 Torr for air-broadening and 453 Torr for self-broadening.
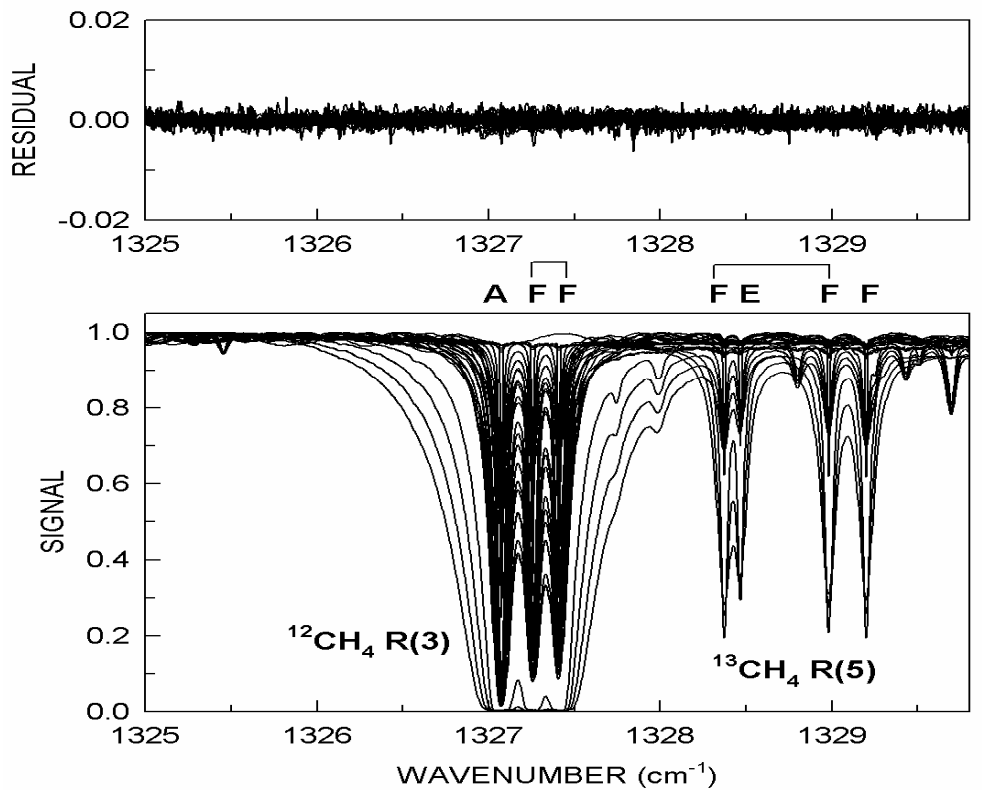

FIGURE 3. Fit, including line mixing, of 31 spectra in the region of the $\mathrm{R}(3)$ manifold of ${ }^{12} \mathrm{CH}_{4}$. The data set includes 3 room-temperature spectra of air-broadened ${ }^{13} \mathrm{CH}_{4}, 26$ spectra of air-broadened "natural" $\mathrm{CH}_{4}$ at $210 \mathrm{~K}$ to $314 \mathrm{~K}$, and one spectrum each of low-pressure pure ${ }^{12} \mathrm{CH}_{4}$ and ${ }^{13} \mathrm{CH}_{4}$. Horizontal lines with ticks indicate which transitions are mixing with each other. 
The parameters resulting from this fit of the $\mathrm{R}(3)$ region are shown in Table 1 . The air-broadened widths and temperature dependences, as well as shifts of unmixed lines, retrieved using the multispectrum fits are in excellent agreement with earlier values determined from single-spectrum fits $[4,5]$. Furthermore, the parameters determined from multispectrum fits show smaller statistical errors than the corresponding parameters resulting from single-spectrum fits of largely the same data set. Since the ${ }^{13} \mathrm{CH}_{4}$ spectra included in the fit were all recorded at room temperature, no information on the temperature-dependence of parameters for the ${ }^{13} \mathrm{CH}_{4} \mathrm{R}(5)$ transitions could be determined, and these were held fixed to average values estimated from corresponding ${ }^{12} \mathrm{CH}_{4} \mathrm{R}(5)$ transitions.

TABLE 1. Methane Air-broadening, Shift, and Line Mixing Parameters in the R(3) Region

\begin{tabular}{|c|c|c|c|c|c|c|c|}
\hline $\begin{array}{c}\text { Position } \\
\left(\mathrm{cm}^{-1}\right)\end{array}$ & $\begin{array}{c}\text { Isotope } \\
\text { and } \\
\text { HITRAN04 } \\
\text { Assignment }\end{array}$ & $\begin{array}{c}\text { Width } \\
\left(\mathrm{cm}^{-1} \mathrm{~atm}^{-1}\right. \\
\text { at } 296 \mathrm{~K})\end{array}$ & $\bar{n}$ & $\begin{array}{c}\text { Shift } \\
\left(\mathrm{cm}^{-1} \mathrm{~atm}^{-1}\right. \\
\text { at } 296 \mathrm{~K})\end{array}$ & $\begin{array}{c}\delta^{\prime} \\
\left(\mathrm{cm}^{-1} \text { atm }^{-1}\right. \\
\left.K^{-1}\right)\end{array}$ & $\begin{array}{c}\text { Mixing } \\
\left(\mathrm{cm}^{-1} \mathrm{~atm}^{-1}\right. \\
\text { at } 296 \mathrm{~K})\end{array}$ & $\begin{array}{c}\mathrm{T}- \\
\text { Dependence } \\
\text { of Mixing }\end{array}$ \\
\hline $1327.074206(4)$ & $\begin{array}{l}12 \mathrm{CH} 4 \\
4 \mathrm{~A} 11 \longleftarrow 3 \mathrm{~A} 21\end{array}$ & $\begin{array}{l}0.05836(2) \\
0.0574(3)\end{array}$ & $\begin{array}{l}0.723(2) \\
0.81(3)\end{array}$ & $\begin{array}{l}-0.00164(2) \\
-0.0018(1)\end{array}$ & $\begin{array}{l}0.85(3) \times 10^{-5} \\
0.7(2) \times 10^{-5}\end{array}$ & none & none \\
\hline $\begin{array}{l}1327.256817(5) \\
*\end{array}$ & $\begin{array}{l}12 \mathrm{CH} 4 \\
4 \mathrm{~F} 1 \quad 1 \leftarrow 3 \mathrm{~F} 21 \\
\end{array}$ & $\begin{array}{l}0.06626(5) \\
0.0667(3)\end{array}$ & $\begin{array}{l}0.802(2) \\
0.64(2)\end{array}$ & $\begin{array}{l}-0.00145(3) \\
+0.0023(3) \\
\end{array}$ & $\begin{array}{l}1.17(6) \times 10^{-5} \\
1.0(3) \times 10^{-5}\end{array}$ & $0.00608(3)$ & $1.32(2)$ \\
\hline $\begin{array}{l}1327.409813(8) \\
*\end{array}$ & $\begin{array}{l}12 \mathrm{CH} 4 \\
4 \mathrm{~F} 2 \quad 1 \leftarrow 3 \mathrm{~F} 11\end{array}$ & $\begin{array}{l}0.06689(3) \\
0.0662(3)\end{array}$ & $\begin{array}{l}0.818(2) \\
0.74(3)\end{array}$ & $\begin{array}{l}-0.00157(3) \\
-0.0050(2)\end{array}$ & $\begin{array}{l}0.60(5) \times 10^{-5} \\
0.5(3) \times 10^{-5}\end{array}$ & $0.00608(3)$ & $1.32(2)$ \\
\hline $\begin{array}{l}1328.372213(9) \\
* *\end{array}$ & $\begin{array}{l}13 \mathrm{CH} 4 \\
6 \mathrm{~F} 21 \leftarrow 5 \mathrm{~F} 12\end{array}$ & $\begin{array}{l}0.05958(4) \\
0.0578(2)\end{array}$ & $\begin{array}{l}0.72 \\
\text { (fixed) }\end{array}$ & $\begin{array}{l}-0.00190(4) \\
-0.0016(2)\end{array}$ & 0.0 (fixed) & $0.00978(27)$ & 1.4 (fixed) \\
\hline $1328.467453(12)$ & $\begin{array}{l}13 \mathrm{CH} 4 \\
6 \mathrm{E} 1 \longleftarrow 5 \mathrm{E} 1\end{array}$ & $\begin{array}{l}0.05169(5) \\
0.0516(1) \\
\end{array}$ & $\begin{array}{l}0.72 \\
\text { (fixed) }\end{array}$ & $\begin{array}{l}-0.00198(4) \\
-0.0026(1) \\
\end{array}$ & 0.0 (fixed) & none & none \\
\hline $\begin{array}{l}1328.982458(9) \\
* *\end{array}$ & $\begin{array}{l}13 \mathrm{CH} 4 \\
6 \mathrm{~F} 11 \leftarrow 5 \mathrm{~F} 21\end{array}$ & $\begin{array}{l}0.06180(4) \\
0.0611(0)\end{array}$ & $\begin{array}{l}0.72 \\
\text { (fixed) }\end{array}$ & $\begin{array}{l}-0.00252(5) \\
-0.0036(1)\end{array}$ & 0.0 (fixed) & $0.00978(27)$ & 1.4 (fixed) \\
\hline $1329.200880(9)$ & $\begin{array}{l}13 \mathrm{CH} 4 \\
6 \mathrm{~F} 22 \leftarrow 5 \mathrm{~F} 11\end{array}$ & $\begin{array}{l}0.05894(4) \\
0.0584(1)\end{array}$ & $\begin{array}{l}0.72 \\
\text { (fixed) }\end{array}$ & $\begin{array}{l}-0.00193(5) \\
-0.0029(2)\end{array}$ & 0.0 (fixed) & $\begin{array}{l}\text { Not } \\
\text { measurable }\end{array}$ & $\begin{array}{l}\text { Not } \\
\text { measurable }\end{array}$ \\
\hline
\end{tabular}

Numbers in parentheses are statistical errors in units of the last digit quoted. Mixing parameter is the larger off-diagonal matrix element of the pair of mixed lines. Mixed pairs are indicated by $*$ or $* *$ in the first column. Results from previous spectrum-by-spectrum analyses $[4,5]$ are given in italics.

As was the case for $\mathrm{H}_{2} \mathrm{O}$, the inclusion of line mixing was seen to have a greater effect on the retrieved values of the line shifts than on the retrieved values of other parameters. We note that for the transition at $1327.2568 \mathrm{~cm}^{-1}$, the inclusion of line mixing in the fit actually changes the sign of its pressure-induced shift; the magnitude of the shift of its mixing partner at $1327.4098 \mathrm{~cm}^{-1}$ also changes significantly. 
We have presented here only a sampling of line mixing results for a few transitions of $\mathrm{H}_{2} \mathrm{O}$ and $\mathrm{CH}_{4}$. Work is continuing on analysis of line mixing in these and other bands. As a larger database of experimentally-determined line mixing parameters is accumulated, there will be additional opportunities to compare experimental and theoretical mixing parameters, and to compare mixing parameters for different bands of the same molecule.

\section{ACKNOWLEDGMENTS}

The research described in this paper was carried out by the Jet Propulsion Laboratory, California Institute of Technology, Langley Research Center and the College of William and Mary under contracts with the National Aeronautics and Space Administration.

\section{REFERENCES}

1. D. Chris Benner, C. P. Rinsland, V. Malathy Devi, M. A. H. Smith, and D. Atkins, J. Quant. Spectrosc. Radiat. Transfer 53, 705-721 (1995).

2. L. R. Brown, D. Chris Benner, V. Malathy Devi, M. A. H. Smith, and R. A. Toth, J. Mol. Structure 742, 111 $122(2005)$.

3. A. Levy, N. Lacome, and C. Chackerian, Jr., "Collisional Line Mixing" in Spectroscopy of the Earth's Atmosphere and Interstellar Medium, edited by K. Narahari Rao and A. Weber, Academic Press, Boston, Massachusetts, 1992, pp. 261-337.

4. M. A. H. Smith, C. P. Rinsland, V. Malathy Devi, and D. Chris Benner, Spectrochimica Acta 48A, 1257-1272 (1992).

5. V. Malathy Devi, C. P. Rinsland, M. A. H. Smith, and D. Chris Benner, Appl. Opt. 27, 2296-2308 (1988). 